\title{
Efficacy and safety of saxagliptin in combination with metformin compared with sitagliptin in combination with metformin in adult patients with type 2 diabetes mellitus
}

\author{
André J. Scheen ${ }^{1}$, Guillaume Charpentier ${ }^{2}$, Carl Johan Östgren ${ }^{3}$, Åsa Hellqvist ${ }^{4}$, Ingrid Gause-Nilsson ${ }^{4}$ \\ ${ }^{1}$ University of Liège, Division of Diabetes, Nutrition and Metabolic Disorders and Clinical Pharmacology Unit, \\ CHU Liège, Liège, Belgium \\ ${ }^{2}$ Endocrinology-Diabetology Unit, Corbeil-Essonnes Hospital, Essonnes, France \\ ${ }^{3}$ Department of Medical and Health Sciences, Linköping University, Linköping, Sweden \\ ${ }^{4}$ AstraZeneca, Research \& Development, Mölndal, Sweden
}

\begin{abstract}
Background Dipeptidyl peptidase-4 inhibitors improve glycaemic control in patients with type 2 diabetes mellitus when used as monotherapy or in combination with other anti-diabetic drugs (metformin, sulphonylurea, or thiazolidinedione). This 18 -week, phase $3 \mathrm{~b}$, multicentre, double-blind, non-inferiority trial compared the efficacy and safety of two dipeptidyl peptidase- 4 inhibitors, saxagliptin and sitagliptin, in patients whose glycaemia was inadequately controlled with metformin.

Methods Adult type 2 diabetes mellitus patients $(N=801)$ with glycated haemoglobin $\left(\mathrm{HbA}_{1 \mathrm{c}}\right) 6.5-10 \%$ on stable metformin doses (1500-3000 mg/day) were randomized 1:1 to add-on $5 \mathrm{mg}$ saxagliptin or $100 \mathrm{mg}$ sitagliptin once daily for 18 weeks. The primary efficacy analysis was a comparison of the change from baseline $\mathrm{HbA}_{1 \mathrm{c}}$ at week 18 in per-protocol patients. Noninferiority was concluded if the upper limit of the two-sided $95 \%$ confidence interval of the $\mathrm{HbA}_{1 \mathrm{c}}$ difference between treatments was $<0.3 \%$.

Results The adjusted mean changes in $\mathrm{HbA}_{1 \mathrm{c}}$ following the addition of saxagliptin or sitagliptin to stable metformin therapy were -0.52 and $-0.62 \%$, respectively. The between-group difference was $0.09 \%(95 \%$ confidence interval, -0.01 to $0.20 \%$ ), demonstrating noninferiority. Both treatments were generally well tolerated; incidence and types of adverse events were comparable between groups. Hypoglycaemic events, mostly mild, were reported in approximately $3 \%$ of patients in each treatment group. Body weight declined by a mean of $0.4 \mathrm{~kg}$ in both groups.
\end{abstract}

Conclusions Saxagliptin added to metformin therapy was effective in improving glycaemic control in patients with type 2 diabetes mellitus inadequately controlled by metformin alone; saxagliptin plus metformin was noninferior to sitagliptin plus metformin, and was generally well tolerated.

Keywords : DPP-4 inhibitor ; saxagliptin ; sitagliptin ; metformin ; type 2 diabetes mellitus ; combination therapy.

\section{INTRODUCTION}

According to statements by the American Diabetes Association/European Association for the Study of Diabetes and the American Association of Clinical Endocrinologists/American College of Endocrinology, metformin is recommended (unless specifically contraindicated) as a first-line agent for monotherapy and combination therapy for patients with type 2 diabetes mellitus (T2DM). This recommendation is based primarily on metformin's glucose-lowering effects, absence of weight gain, generally low level of side effects, and relatively low cost $[1,2]$. However, many patients, particularly those with higher baseline glycated haemoglobin $\left(\mathrm{HbA}_{1 \mathrm{c}}\right)$ values, may not achieve their glycaemic goals on metformin monotherapy despite titration to maximally tolerated doses, and therefore require additional medication $[1,3,4]$. Patients whose glycaemic control deteriorates over time with metformin monotherapy will require additional anti-diabetic medication. Although multiple classes of anti- 
diabetic agents are available, there remains a need for agents with different mechanisms of action that offer improved efficacy and/or better tolerability profiles and can be used either as monotherapy or in combination treatment regimens (including metformin).

Dipeptidyl peptidase-4 (DPP-4) inhibitors are a class of oral anti-diabetic agents that increase circulating concentrations of the incretin gastrointestinal hormones glucagon-like peptide- 1 and glucose-dependent insulinotropic polypeptide [5]. The incretins are rapidly released after meals and stimulate glucose-dependent insulin secretion. Glucagon-like peptide-1 also inhibits glucagon secretion, thereby attenuating postprandial glucose excursions [6]. The DPP-4 inhibitors improve glycaemic control by blocking the rapid inactivation of incretins, mainly glucagon-like peptide-1 [7-12]. Sitagliptin (Januvia ${ }^{\circledR}$, Merck \& Co, Inc, Whitehouse Station, $\mathrm{NJ}$ ), the first of the DPP-4 inhibitors approved in the United States, has been used as an adjunct to diet and exercise in monotherapy and in combination regimens with other oral anti-diabetic drugs [1,11-13].

The mechanism of action of the DPP-4 inhibitors is complementary to that of metformin, which improves insulin sensitivity and reduces hepatic glucose production [5]. Hypoglycaemia, weight gain, and edema are generally not associated with DPP-4 inhibitor therapy; however, these adverse events have been associated with other antidiabetic drug classes that are often used in conjunction with metformin (e.g. sulphonylureas, glinides, thiazolidinediones, and insulin) [6]. The low propensity for both DPP-4 inhibitors and metformin to cause hypoglycaemia or weight gain makes them an appropriate option for combination therapy in patients who are not meeting their glycaemic goals [5].

Saxagliptin (Onglyza ${ }^{\mathrm{TM}}$, Bristol-Myers Squibb, Princeton, NJ/AstraZeneca, Wilmington, DE) is a potent, selective DPP-4 inhibitor, approved as an adjunct to diet and exercise to treat hyperglycaemia in patients with T2DM [14-16]. In phase 3 clinical trials, saxagliptin added to a stable dose of metformin, sulphonylurea, or thiazolidinedione, or given as initial therapy in combination with metformin, significantly improved glycaemic control and was well tolerated in patients with T2DM [7-9,17]. In a 24-week study in patients whose diabetes was not adequately controlled by stable metformin doses, adding saxagliptin $2.5,5$, or $10 \mathrm{mg}$ daily reduced $\mathrm{HbA}_{1 \mathrm{c}}$ from a baseline of $8.1 \%$, by $0.7,0.8$, and $0.7 \%$, respectively, compared with add-on placebo [7].

The present study represents the first head-to-head comparison between two DPP-4 inhibitors, and was designed to determine whether saxagliptin is effective and well tolerated in the treatment of T2DM and whether it is noninferior to sitagliptin. This 18 -week trial evaluated the safety and efficacy of saxagliptin versus sitagliptin, each in combination with a stable dose of metformin, with a noninferiority assessment of the primary endpoint, in patients with T2DM who had inadequate glycaemic control on metformin alone.

\section{MATERIALS AND METHODS}

\section{Study design}

This 18-week, multicentre, randomized, double-blind, parallel-group, active-controlled phase $3 \mathrm{~b}$ trial was conducted at 99 sites in Argentina (14), Belgium (11), Denmark (9), France (10), Italy (9), Mexico (4), Norway (16), South Africa (12), and Sweden (14). After enrollment, eligible patients entered a 2-week lead-in period, during which they received single-blind placebo, open-label metformin, and counselling on dietary and lifestyle modifications according to usual clinical practice. The dose of open-label metformin was based on each patient's current dose at enrollment, and was to remain stable throughout the study. Patients received metformin at 1500 , 2000,2500 , or $3000 \mathrm{mg}$ /day if their dose at entry was $1500-1999 \mathrm{mg} /$ day, $2000-2499 \mathrm{mg} /$ day, 2500-2550 $\mathrm{mg} /$ day, or $>2550 \mathrm{mg} /$ day, respectively. Patients were also given a glucometer and a diary, and were instructed to monitor their plasma glucose at least every second day during the lead-in period. After 2 weeks, patients who continued to meet eligibility requirements, as defined below, were randomly assigned in a 1:1 ratio to doubleblind treatment with $5 \mathrm{mg}$ saxagliptin once daily (o.d.) or $100 \mathrm{mg}$ sitagliptin o.d. for 18 weeks, while continuing open-label metformin. A double-dummy design with matching placebo tablets for saxagliptin or placebo capsules for sitagliptin was used to ensure blinding. Dietary and lifestyle modification counselling was reinforced during this period, and patients were asked to monitor their plasma glucose at least once weekly. Patients returned to the clinic at 4, 8, 12, and 18 weeks for efficacy and safety assessments.

This study was conducted in accord with the Declaration of Helsinki and in compliance with International Conference on Harmonisation/Good Clinical Practice and all applicable regulatory requirements. The study protocol and informed consent were approved by the Institutional Review Board or Independent Ethics Committee at each study site before that site enrolled any patients. All patients provided written informed consent before participating in this trial. The clinical trial registry number of this study was NCT00666458. 


\section{Patients}

Men and women $\geq 18$ years of age who had been diagnosed with T2DM were eligible to participate if $\mathrm{HbA}_{1 \mathrm{c}}$ remained uncontrolled $\left(\mathrm{HbA}_{1 \mathrm{c}} 6.5-10.0 \%\right.$ ), despite monotherapy with a stable dose of metformin $\geq 1500 \mathrm{mg}$ for at least 8 weeks. Women of childbearing potential were required to have a negative urine pregnancy test, and agreed to use adequate contraception throughout the study and for up to 4 weeks after completion. Enrollment of patients with $\mathrm{HbAi}_{\mathrm{c}}>6.5$ to $<7.0 \%$ was scheduled to stop when the cohort of randomized patients with $\mathrm{HbA}_{1 \mathrm{c}}$ values in this range reached approximately $25 \%$. At that point, the lower bound of $\mathrm{HbA}_{1 \mathrm{c}}$ for enrollment was to be reset at $\geq 7.0 \%$ for the remainder of the study. This contingency was not implemented because the $25 \%$ limit was not reached until the study was fully enrolled.

Patients were excluded if they had received a thiazo-lidinedione within 12 weeks or insulin within 1 year, previous treatment with a DPP-4 inhibitor, or were currently receiving treatment with a cytochrome P450 3A4 inducer, a systemic corticosteroid, or a human immunodeficiency virus anti-viral medication. Patients were also excluded if they had type 1 diabetes; a history of diabetic ketoacidosis or hyperosmolar nonketonic coma; New York Heart Association class III or IV congestive heart failure; left ventricular ejection fraction $\leq 40 \%$; a major cardiovascular event within the past 6 months; haemoglobinopathy; a recent history of alcohol or drug abuse; or any contraindication listed in the package inserts of the study drugs. Other exclusion criteria determined at the lead-in visit were serum creatinine $\geq 133 \mu \mathrm{mol} / \mathrm{L}(\geq 1.5 \mathrm{mg} / \mathrm{dL})$ in men or $\geq 124 \mu \mathrm{mol} / \mathrm{L}(\geq 1.4 \mathrm{mg} / \mathrm{dL})$ in women; abnormal liver function, defined as aspartate aminotransferase or alanine aminotransferase $>2$ times the upper limit of normal or total bilirubin $>34 \mu \mathrm{mol} / \mathrm{L}(>2 \mathrm{mg} / \mathrm{dL})$; creatine kinase $\geq 3$ times the upper limit of normal; or a history of positive serologic evidence of infectious liver disease. In addition, patients with clinically significant abnormalities identified on physical examination, laboratory testing, or electrocardiogram were excluded if, in the judgement of the investigator, the abnormality would compromise patient safety or successful participation in the study.

Patients could be discontinued from the study for the following reasons: voluntary discontinuation; safety; noncompliance with the study protocol; lost to follow-up; use or need of anti-hyperglycaemic medications other than metformin and the study drugs for more than 14 consecutive days (insulin during hospitalization was allowed); or severe and/or frequent hypoglycaemic events. Other causes for discontinuation were development of studyspecified discontinuation criteria, including a confirmed fasting plasma glucose (FPG) $>15.0 \mathrm{mmol} / \mathrm{L}(>270$ $\mathrm{mg} / \mathrm{dL})$ at 4 weeks, $>13.3 \mathrm{mmol} / \mathrm{L}(>240 \mathrm{mg} / \mathrm{dL})$ at 8 weeks, or $>12.2 \mathrm{mmol} / \mathrm{L}(>220 \mathrm{mg} / \mathrm{dL})$ at 12 weeks; confirmed absolute lymphocyte count $\leq 400$ cells $/ \mu \mathrm{L}$ or thrombocyte count $<75000$ cells $/ \mu \mathrm{L}$; or a confirmed increase in serum creatinine to $\geq 133 \mu \mathrm{mol} / \mathrm{L}(\geq 1.5 \mathrm{mg} / \mathrm{dL})$ in men or $\geq 124 \mu \mathrm{mol} / \mathrm{L}(\geq 1.4 \mathrm{mg} / \mathrm{dL})$ in women.

\section{Efficacy assessments}

$\mathrm{HbA}_{1 \mathrm{c}}$ and FPG were measured at baseline and at 4, 8, 12, and 18 weeks of the double-blind treatment period; fasting insulin, proinsulin, C-peptide, and glucagon were determined at baseline and after 18 weeks.

The primary efficacy variable was absolute change in $\mathrm{HbA}_{1 \mathrm{c}}$ from baseline to week 18 . Secondary efficacy variables included proportion of patients achieving a therapeutic glycaemic response (defined as $\mathrm{HbA}_{1 \mathrm{c}} \leq 6.5 \%$ ); proportion of patients with baseline $\mathrm{HbA}_{1 \mathrm{c}} \geq 7.0 \%$ achieving a therapeutic glycaemic response (defined as $\mathrm{HbA}_{1 \mathrm{c}}$ $<7.0 \%$ ); change from baseline FPG, insulin, C-peptide, and proinsulin; and change from baseline $\beta$-cell function, as measured by the homeostasis model assessment- $2 \beta$ [18].

\section{Safety assessments}

Adverse events, clinical laboratory testing, physical examinations, and vital signs were monitored at each study visit during the double-blind treatment period, and 12-lead electrocardiograms were performed at the first and last visits. All adverse events were evaluated by the investigator according to their intensity and potential causal relationship to study medication, then coded by the sponsor using the Medical Dictionary for Regulatory Activities, version 11.1. Patients also self-monitored their plasma glucose levels and were instructed to record symptoms suggestive of hypoglycaemia in their diaries. Hypoglycaemic events were defined in accord with the guidelines of the Committee for Proprietary Medicinal Products for clinical investigation of medications for treatment of diabetes [19]. A hypoglycaemic adverse event was classified as a major event if it was associated with at least one symptom, required external assistance (defined as medical assistance or help from family/friend/other) to be resolved, had an associated plasma glucose $<3.5 \mathrm{mmol} / \mathrm{L}(<63 \mathrm{mg} / \mathrm{dL})$, and had prompt recovery (defined as the start and stop of the event occurring on the same date). A hypoglycaemic adverse event was classified as a minor event if it had at least one symptom recorded with plasma glucose $<3.5$ 
$\mathrm{mmol} / \mathrm{L}(<63 \mathrm{mg} / \mathrm{dL})$ and no need for assistance, or an asymptomatic plasma glucose measurement $<3.5 \mathrm{mmol} / \mathrm{L}$ $(<63 \mathrm{mg} / \mathrm{dL})$. Events suggestive of hypoglycaemia were those with at least one symptom, but with no plasma glucose measurement or plasma glucose $\geq 3.5 \mathrm{mmol} / \mathrm{L}(\geq 63 \mathrm{mg} / \mathrm{dL})$. In addition, selected skin disorders were defined according to Medical Dictionary for Regulatory Activities preferred terms as being potentially correlative to skin findings observed in monkeys treated with saxagliptin. This list was compiled before the study was unblinded.

\section{Statistical analyses}

The primary efficacy analysis evaluated whether saxagliptin plus metformin was noninferior to sitagliptin plus metformin in reducing $\mathrm{HbA}_{1 \mathrm{c}}$ from baseline to week 18 in the per-protocol population, which included all patients who had no significant protocol deviations and completed the 18 -week treatment period. This comparison between treatment groups for the adjusted mean change in $\mathrm{HbA}_{1 \mathrm{c}}$ was made using an analysis of covariance model, with treatment group as a fixed effect and baseline $\mathrm{HbA}_{1 \mathrm{c}}$ as a covariate. Point estimates and two-sided 95\% confidence intervals (CIs) for the difference in adjusted mean change from baseline in the two treatment groups were estimated from the model, and a conclusion of noninferiority was reached if the upper limit of the two-sided $95 \% \mathrm{CI}$ of the difference in $\mathrm{HbA}_{1 \mathrm{c}}$ change from baseline to week 18 was $<0.3 \%$. A confirmatory analysis of the adjusted mean change from baseline $\mathrm{HbA}_{1 \mathrm{c}}$ was conducted in the full analysis set using a last-observation-carried-forward approach, which included all patients who received at least one dose of study medication and had at least one baseline and one postbaseline efficacy data assessment. This analysis used an analysis of covariance model, with treatment group as a fixed effect and baseline $\mathrm{HbA}_{1 \mathrm{c}}$ as a covariate. A sample size of 710 patients (or 355 per treatment group) was estimated to have $90 \%$ power to establish the noninferiority between treatment groups at the 5\% level, assuming that the standard deviation of the change from baseline $\mathrm{HbA}_{1 \mathrm{c}}$ was $1.1 \%$, with a noninferiority limit set at $0.3 \%$ and an assumed zero true difference between treatment groups. The sample size also assumed that $20 \%$ of randomized patients would be excluded from the per-protocol analysis set.

A similar analysis of covariance model was used to compare secondary continuous efficacy variables between treatment groups, adjusted for the baseline value of that variable (e.g. changes in FPG from baseline to week 18 were adjusted for baseline FPG). For categorical variables, such as the proportion of patients achieving a therapeutic glycaemic response, the frequency and percentage were calculated, and the percent difference between treatments and 95\% CI were estimated using the Fisher exact test. No a priori hypotheses were proposed for secondary efficacy variables and, therefore, only the $95 \%$ CIs are provided for these values. Safety variables were analysed using descriptive statistics for all patients who received at least one dose of study medication.

\section{RESULTS}

\section{Patient disposition}

Of the 822 patients who entered the lead-in period, 21 patients did not enter the randomized, double-blind treatment period. Reasons for these patients not entering the randomized, double-blind treatment period included withdrawal of consent, incorrect enrollment, and poor compliance or noncompliance. A total of 801 patients with T2DM whose glycaemia remained inadequately controlled with metformin monotherapy were randomly allocated to $5 \mathrm{mg}$ saxagliptin o.d. added to ongoing metformin ( $n=403$ patients) or $100 \mathrm{mg}$ sitagliptin o.d. added to ongoing metformin $(n=398)$ (Figure 1). More than $90 \%$ of patients in both treatment groups completed the 18-week double-blind treatment period. Reasons for discontinuation were generally similar between treatment groups, although more patients discontinued from the saxagliptin group than from the sitagliptin group because of development of study-specified discontinuation criteria (3.5 versus $1.8 \%$ ), most commonly FPG $>12.2$ $\mathrm{mmol} / \mathrm{L}(>220 \mathrm{mg} / \mathrm{dL})$ at week 12 (2.0 versus $0.8 \%)$.

\section{Patient demographics and baseline characteristics}

Demographic and clinical characteristics of study patients were generally well balanced between treatment groups (Table 1). Overall, the study cohort had a mean age of 58.4 years and included 231 patients $(28.8 \%) \geq 65$ years of age. The majority were white $(66.4 \%)$, and most were obese, with body mass index $\geq 30 \mathrm{~kg} / \mathrm{m}^{2}(53.6 \%)$. For the entire cohort, mean duration of T2DM was 6.3 years, with approximately $20 \%$ having a diabetes duration $\geq 10$ years. At baseline, mean $\mathrm{HbA}_{1 \mathrm{c}}$ was $7.7 \%$, mean FPG was $8.9 \mathrm{mmol} / \mathrm{L}(160 \mathrm{mg} / \mathrm{dL})$, and the mean metformin dose was $1829 \mathrm{mg} /$ day. Baseline characteristics in the per-protocol analysis set $(n=677)$ were similar to those for the randomized study cohort $(N=801)$. 
Figure 1. Patient disposition

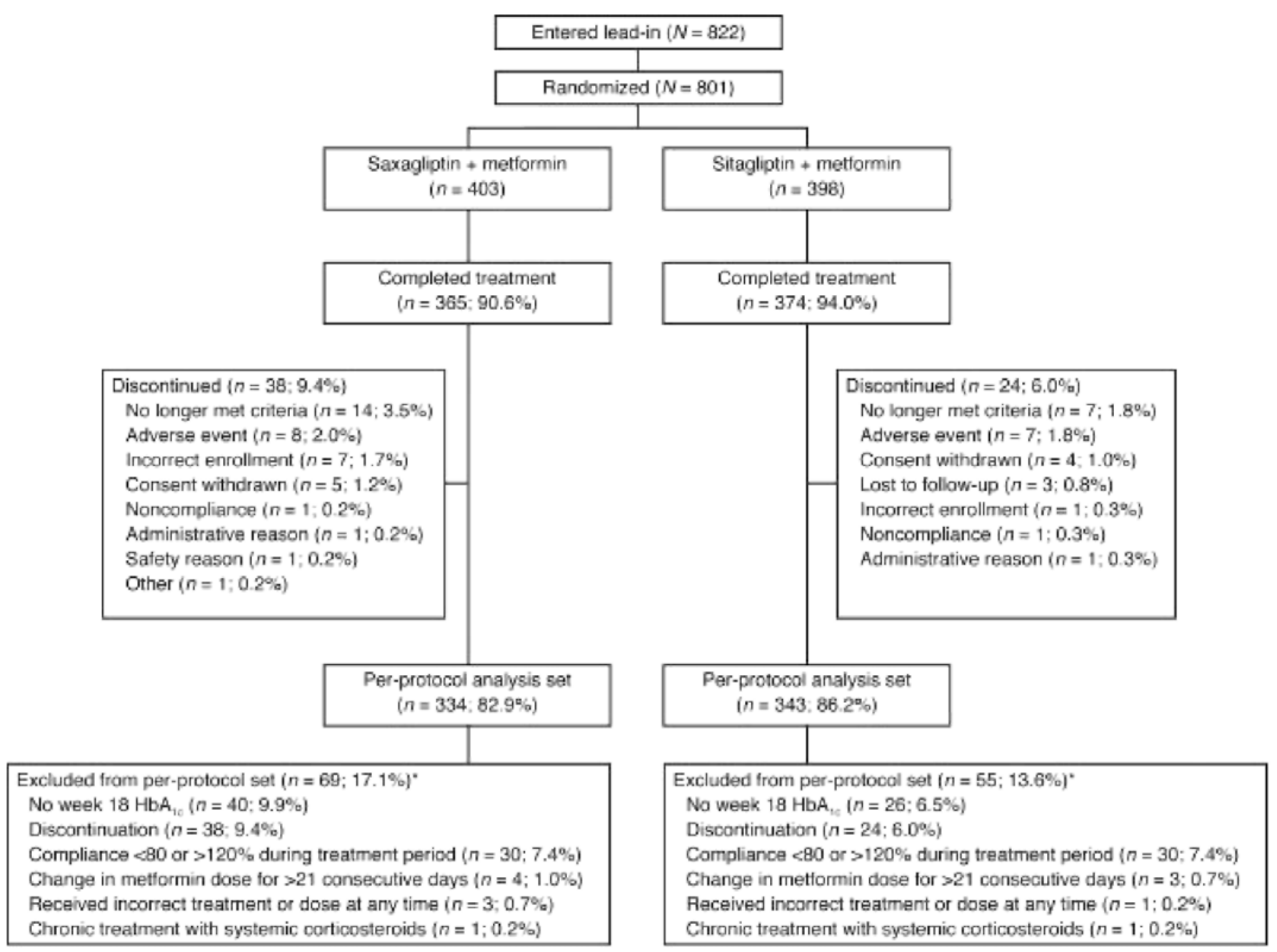

-Patient may have had more than 1 reason for exclusion from per-protocol analysis set. 
Table 1. Patient demographics and key baseline characteristics

\begin{tabular}{|c|c|c|c|}
\hline & $\begin{array}{c}\text { Saxagliptin }+ \text { metformin } \\
(n=403)\end{array}$ & $\begin{array}{c}\text { Sitagliptin + metformin } \\
(n=398)\end{array}$ & $\begin{array}{c}\text { Total } \\
(N=801)\end{array}$ \\
\hline \multicolumn{4}{|l|}{ Age (years) } \\
\hline Mean (SD) & $58.8(10.1)$ & $58.1(10.5)$ & $58.4(10.3)$ \\
\hline$\geq 65$ years, $n(\%)$ & $111(27.5)$ & $120(30.2)$ & $231(28.8)$ \\
\hline \multicolumn{4}{|l|}{ Gender, $n$ (\%) } \\
\hline Male & $190(47.1)$ & $202(50.8)$ & $392(48.9)$ \\
\hline Female & $213(52.9)$ & $196(49.2)$ & $409(51.1)$ \\
\hline \multicolumn{4}{|l|}{ Race, $n$ (\%) } \\
\hline White & $273(67.7)$ & $259(65.1)$ & $532(66.4)$ \\
\hline Asian & $34(8.4)$ & $40(10.1)$ & $74(9.2)$ \\
\hline Black/African American & $29(7.2)$ & $30(7.5)$ & $59(7.4)$ \\
\hline American Indian/Alaskan native & $25(6.2)$ & $25(6.3)$ & $50(6.2)$ \\
\hline Other & $42(10.4)$ & $44(11.1)$ & $86(10.7)$ \\
\hline \multicolumn{4}{|l|}{ Geographic region, $n$ (\%) } \\
\hline Europe & $208(51.6)$ & $201(50.5)$ & $409(51.1)$ \\
\hline Latin America & $126(31.3)$ & $127(31.9)$ & $253(31.6)$ \\
\hline South Africa & $69(17.1)$ & $70(17.6)$ & $139(17.4)$ \\
\hline \multicolumn{4}{|l|}{ Body mass index $\left(\mathrm{kg} / \mathrm{m}^{2}\right)$} \\
\hline Mean (SD) & $31.1(5.3)$ & $30.9(5.5)$ & $31.0(5.4)$ \\
\hline$\geq 30 \mathrm{~kg} / \mathrm{m}^{2}, n(\%)$ & $222(55.1)$ & $207(52.0)$ & $429(53.6)$ \\
\hline \multicolumn{4}{|c|}{ Duration of type 2 diabetes mellitus (years) } \\
\hline Mean (SD) & $6.3(5.0)$ & $6.3(4.7)$ & $6.3(4.9)$ \\
\hline Duration $\geq 5$ years, $n(\%)$ & $220(54.6)$ & $204(51.3)$ & $424(52.9)$ \\
\hline Duration $\geq 10$ years, $n(\%)$ & $73(18.1)$ & $85(21.4)$ & $158(19.7)$ \\
\hline \multicolumn{4}{|l|}{ Baseline parameters, mean (SD) } \\
\hline Glycated haemoglobin (\%) & $7.7(1.0)$ & $7.7(0.9)$ & $7.7(0.9)$ \\
\hline Fasting plasma glucose $(\mathrm{mmol} / \mathrm{L})$ & $8.9(2.5)$ & $8.9(2.4)$ & $8.9(2.5)$ \\
\hline Fasting insulin $(\mathrm{pmol} / \mathrm{L})$ & $90.8(82.3)$ & $84.4(77.4)$ & $87.6(79.9)$ \\
\hline \multicolumn{4}{|l|}{ Metformin dose (mg/day) } \\
\hline Mean (SD) & $1831.5(463.5)$ & $1826.2(480.7)$ & $1828.8(471.8)$ \\
\hline$\geq 1500-<2000, n(\%)$ & $233(57.8)$ & $245(61.6)$ & $478(59.7)$ \\
\hline$\geq 2000-<2500, n(\%)$ & 99 (24.6) & $76(19.1)$ & $175(21.8)$ \\
\hline$\geq 2500-<3000, n(\%)$ & $45(11.2)$ & $45(11.3)$ & $90(11.2)$ \\
\hline$\geq 3000, n(\%)$ & $25(6.2)$ & $31(7.8)$ & $56(7)$ \\
\hline Not reported & $1(0.2)$ & $1(0.3)$ & $2(0.2)$ \\
\hline
\end{tabular}

SD, standard deviation.

Table 2. Statistical analysis of the changes in $\mathrm{Hb} A_{1 c}$ from baseline to week 18 after the addition of saxagliptin or sitagliptin to metformin therapy in the per-protocol analysis set

\begin{tabular}{|c|c|c|}
\hline & $\begin{array}{l}\text { Saxagliptin }+ \text { metformin } \\
\qquad(n=334)\end{array}$ & $\begin{array}{l}\text { Sitagliptin }+ \text { metformin } \\
\qquad(n=343)\end{array}$ \\
\hline Mean $(\mathrm{SE}) \mathrm{HbA}_{1 \mathrm{c}}$ at baseline $(\%)$ & $7.68(0.052)$ & $7.69(0.047)$ \\
\hline Mean $(\mathrm{SE}) \mathrm{HbA}_{1 \mathrm{c}}$ at week $18(\%)$ & $7.16(0.052)$ & $7.07(0.051)$ \\
\hline \multicolumn{3}{|l|}{ Adjusted change from baseline $\mathrm{HbA}_{1 \mathrm{c}}(\%)$} \\
\hline Mean (SE) & $-0.52(0.039)$ & $-0.62(0.038)$ \\
\hline Two-sided 95\% confidence interval & $-0.60,-0.45$ & $-0.69,-0.54$ \\
\hline \multicolumn{3}{|c|}{$\begin{array}{l}\text { Difference in adjusted change from baseline } \mathrm{HbA}_{1 \mathrm{c}} \\
\text { versus sitagliptin plus metformin (\%) }\end{array}$} \\
\hline Mean (SE) & $0.09(0.055)$ & - \\
\hline Two-sided $95 \%$ confidence interval & $-0.01,0.20$ & - \\
\hline
\end{tabular}


Figure 2. Mean ( $\pm S E)$ glycated haemoglobin $\left(H b A_{I c}\right)$ values at each visit during the double-blind treatment period. MET, metformin; SAXA, saxagliptin; SITA, sitagliptin

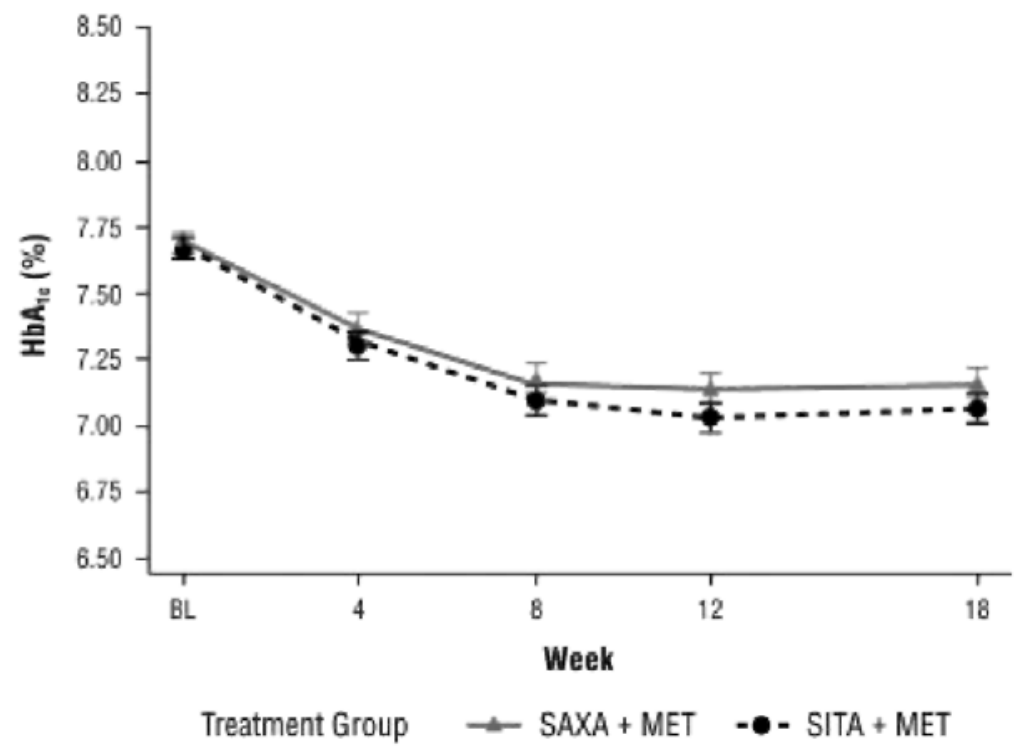

\section{Efficacy}

Based on the per-protocol analysis set, the addition of saxagliptin or sitagliptin to metformin therapy produced similar decreases in mean $\mathrm{HbA}_{1 \mathrm{c}}$ from baseline to week 18 (Table 2). Mean $\mathrm{HbA}_{\mathrm{lc}}$ declined from 7.68 to $7.16 \%$ in the saxagliptin plus metformin group; the adjusted mean $( \pm \mathrm{SE})$ change was $-0.52 \%( \pm 0.039)(95 \% \mathrm{CI},-0.60$ to $-0.45 \%$ ). Similarly, mean $\mathrm{HbA}_{1 \mathrm{c}}$ declined from 7.69 to $7.07 \%$ in the sitagliptin plus metformin group, an adjusted mean change of $-0.62 \%( \pm 0.038)(95 \% \mathrm{CI},-0.69$ to $-0.54 \%)$. The difference between groups in the adjusted mean change from baseline $\mathrm{HbA}_{1 \mathrm{c}}$ was $0.09 \%$ (95\% CI, -0.01 to $0.20 \%$ ). The upper limit of this $95 \% \mathrm{CI}$ was below the predefined criterion for noninferiority of $<0.3 \%$. Thus, saxagliptin added to metformin was noninferior to sitagliptin added to metformin. The results of the per-protocol analysis were confirmed in the full cohort analysis set, in which the adjusted mean change in $\mathrm{HbA}_{1 \mathrm{c}}$ from baseline to week 18 was $-0.42 \%$ for saxagliptin plus metformin and $-0.59 \%$ for sitagliptin plus metformin. In this data set, the difference between groups in the adjusted mean change from baseline $\mathrm{HbA}_{1 \mathrm{c}}$ was $0.17 \%(95 \% \mathrm{CI}, 0.06-0.28 \%)$, with the upper limit of the $95 \%$ CI also below the predefined noninferiority criterion of $<0.3 \%$. Median changes from baseline to week 18 in $\mathrm{HbA}_{1 \mathrm{c}}$ values in the full cohort analysis set were $-0.50 \%$ in both treatment groups. The reduction in $\mathrm{HbA}_{1 \mathrm{c}}$ seen after the addition of saxagliptin or sitagliptin to metformin therapy was achieved within the first 8 weeks and was maintained until the end of the study in both groups (Figure 2).

The proportion of patients achieving therapeutic glycaemic responses was similar in the two treatment groups (Figure 3). Overall, 105 of 399 patients $(26.3 \%)$ who received saxagliptin plus metformin compared with 114 of 392 patients (29.1\%) who received sitagliptin plus metformin achieved an $\mathrm{HbA}_{1 \mathrm{c}} \leq 6.5 \%$ at week 18 . The difference between treatments (saxagliptin versus sitagliptin) in glycaemic response rate was $-2.8 \%$ (95\% CI, 9.0 to $3.5 \%$ ). For those with an $\mathrm{HbA}_{1 \mathrm{c}} \geq 7.0 \%$ at baseline, 97 of 294 patients $(33.0 \%)$ in the saxagliptin plus metformin group and 117 of 299 patients $(39.1 \%)$ in the sitagliptin plus metformin group achieved an $\mathrm{HbA}_{1 \mathrm{c}}<$ $7.0 \%$ at week 18 , a $-6.1 \%$ difference between groups (95\% CI, -13.8 to $1.6 \%)$.

Improvements in glycaemic control were also observed as decreases in FPG from baseline to week 18 (Table 3). Adding saxagliptin or sitagliptin to metformin therapy produced adjusted mean changes in FPG of $-0.60 \mathrm{mmol} / \mathrm{L}$ $(-10.8 \mathrm{mg} / \mathrm{dL})$ and $-0.90 \mathrm{mmol} / \mathrm{L}(-16.2 \mathrm{mg} / \mathrm{dL})$, respectively. The mean difference was $0.30 \mathrm{mmol} / \mathrm{L}(5.42$ $\mathrm{mg} / \mathrm{dL}) ; 95 \%$ CI, 0.08-0.53 mmol/L (1.37-9.47 mg/dL). There were no apparent differences between treatment groups for the changes from baseline in fasting insulin, glucagon, proinsulin, or C-peptide (Table 3). Similarly, the small improvement in $\beta$-cell function, as measured by the change from baseline in homeostasis model assessment- $2 \beta$, did not differ between the two treatment groups (Table 3 ). 
Figure 3. Proportion of patients achieving glycaemic response with glycated haemoglobin (HbA $\left.A_{I c}\right) \leq 6.5 \%$ at week 18 , and proportion of patients with baseline $H b A_{1 c} \geq 7.0 \%$ achieving $H b A_{1 c}<7.0 \%$ at week 18 . Saxagliptin $(S A X A)+$ metformin $(M E T) H b A_{l c} \leq 6.5 \%, n=399 ;$ sitagliptin $(S I T A)+M E T H b A_{l c} \leq 6.5 \%, n=392 ; S A X A+$ MET HbA $A_{l c} \leq 7.0 \%, n=294 ;$ SITA + MET HbA $1 c \leq 7.0 \%, n=299$

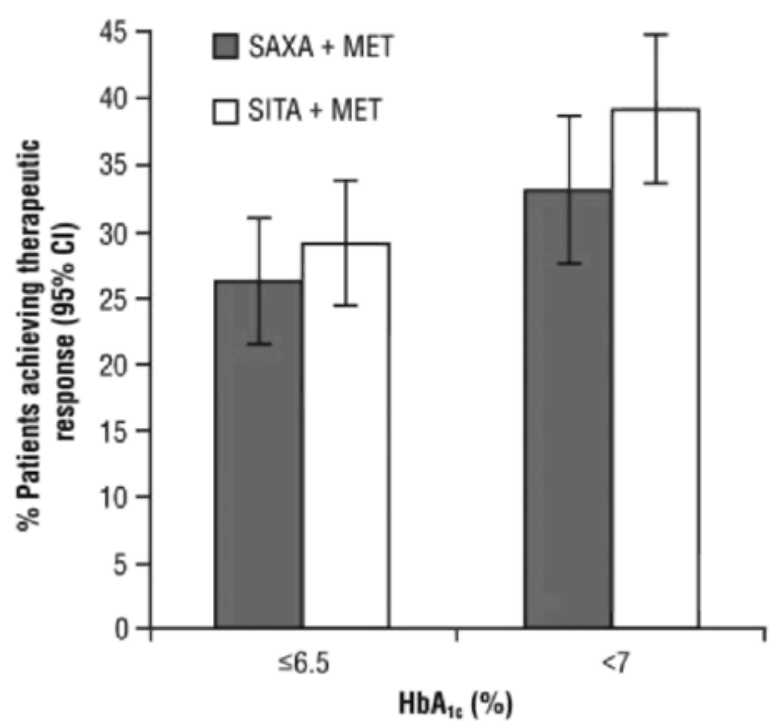

Table 3. Changes from baseline to week 18 in secondary efficacy variables in the full analysis cohort

\begin{tabular}{|c|c|c|c|}
\hline & $\begin{array}{l}\text { Saxagliptin }+ \text { metformin } \\
(n=397)\end{array}$ & $\begin{array}{c}\text { Sitagliptin + metformin } \\
(n=392) \\
\end{array}$ & $\begin{array}{l}\text { Mean difference } \\
\text { between groups }{ }^{\mathrm{a}}\end{array}$ \\
\hline \multicolumn{4}{|l|}{ Fasting plasma glucose (mmol/L) } \\
\hline Mean (SE) at baseline & $8.86(0.127)$ & $8.89(0.122)$ & - \\
\hline Mean (SE) at week 18 & $8.27(0.111)$ & $7.99(0.103)$ & - \\
\hline Adjusted mean change (SE) from baseline & $-0.60(0.081)$ & $-0.90(0.081)$ & $0.30(0.115)$ \\
\hline $95 \% \mathrm{CI}$ & $-0.75,-0.44$ & $-1.06,-0.74$ & $0.08,0.53$ \\
\hline Fasting insulin ( $\mu \mathrm{mol} / \mathrm{L})$ & $n=354$ & $n=357$ & \\
\hline Mean (SE) at baseline & $92.7(4.50)$ & $82.9(4.08)$ & - \\
\hline Mean (SE) at week 18 & $89.4(3.35)$ & $82.7(3.32)$ & - \\
\hline Adjusted mean change (SE) from baseline & $-0.5(2.79)$ & $-3.0(2.78)$ & $2.5(3.94)$ \\
\hline $95 \% \mathrm{CI}$ & $-5.9,5.0$ & $-8.4,2.5$ & $-5.2,10.2$ \\
\hline Fasting glucagon (pmol/L) & $n=343$ & $n=339$ & \\
\hline Mean (SE) at baseline & $22.0(0.49)$ & $22.0(0.53)$ & - \\
\hline Mean (SE) at week 18 & $21.9(0.49)$ & $21.0(0.43)$ & - \\
\hline Adjusted mean change (SE) from baseline & $-0.1(0.39)$ & $-1.0(0.39)$ & $0.9(0.55)$ \\
\hline $95 \% \mathrm{CI}$ & $-0.9,0.7$ & $-1.8,-0.2$ & $-0.2,2.0$ \\
\hline Fasting proinsulin (pmol/L) & $n=359$ & $n=358$ & \\
\hline Mean (SE) at baseline & $29.1(1.86)$ & $25.0(1.20)$ & - \\
\hline Mean (SE) at week 18 & $26.0(1.52)$ & $22.4(1.07)$ & - \\
\hline Adjusted mean change (SE) from baseline & $-2.4(0.87)$ & $-3.4(0.87)$ & $1.0(1.23)$ \\
\hline $95 \% \mathrm{CI}$ & $-4.1,-0.7$ & $-5.1,-1.7$ & $-1.4,3.4$ \\
\hline Fasting C-peptide (nmol/L) & $n=332$ & $n=342$ & \\
\hline Mean (SE) at baseline & $1.01(0.031)$ & $0.94(0.028)$ & - \\
\hline Mean (SE) at week 18 & $1.04(0.028)$ & $0.96(0.027)$ & - \\
\hline Adjusted mean change (SE) from baseline & $0.05(0.022)$ & $0.01(0.021)$ & $0.04(0.030)$ \\
\hline $95 \% \mathrm{CI}$ & $0.00,0.09$ & $-0.03,0.05$ & $-0.02,0.10$ \\
\hline Homeostasis model assessment- $2 \beta(\%)$ & $n=324$ & $n=334$ & \\
\hline Mean (SE) at baseline & $69.6(2.23)$ & $63.5(1.97)$ & - \\
\hline Mean (SE) at week 18 & $79.8(2.43)$ & $77.4(2.08)$ & - \\
\hline Adjusted mean change (SE) from baseline & $11.0(1.61)$ & $13.1(1.58)$ & $-2.2(2.26)$ \\
\hline $95 \% \mathrm{CI}$ & $7.8,14.1$ & $10.0,16.3$ & $-6.6,2.3$ \\
\hline
\end{tabular}

CI, confidence interval; SE, standard error.

${ }^{a}$ Difference in adjusted mean change from baseline to week 18 with saxagliptin + metformin versus sitagliptin + metformin. 


\section{Safety}

The safety profile of the combination of saxagliptin plus metformin was similar to that of sitagliptin plus metformin. Overall, the incidence of reported adverse events during the 18 -week treatment period was $47.1 \%$ among patients treated with saxagliptin plus metformin and $47.2 \%$ among those given sitagliptin plus metformin (Table 4). In general, the incidence and types of adverse events when classified by system organ class or preferred term according to the Medical Dictionary for Regulatory Activities were similar between treatment groups. The most common adverse events were influenza, urinary tract infection, and nasopharyngitis (Table 4). Overall, nine patients in each treatment group discontinued due to adverse events. By system organ class, the most common adverse events were infections and infestations (occurring in $25.1 \%$ of patients in each treatment group), gastrointestinal disorders (occurring in 9.2 versus $10.6 \%$ of patients in the saxagliptin and sitagliptin groups, respectively), and musculoskeletal and connective tissue disorders (7.2 versus $8.3 \%$ ).

Twelve serious adverse events ( 7 in the saxagliptin group and 5 in the sitagliptin group) were reported during the study, but only 3 of these events ( 1 in the saxagliptin group and 2 in the sitagliptin group) were considered by the investigator to be related to study treatment. In the saxagliptin group, a woman 59 years of age developed hyperglycaemia after treatment for 41 days, leading to discontinuation of study treatment. In the sitagliptin group, a woman 56 years of age had hypoglycaemia after 113 days of treatment (physical activity was a contributing factor), and a woman 46 years of age had hypoglycaemia after 75 days of treatment (no known contributing factor). Study drug was interrupted in the second case. The patients with treatment-related serious adverse events recovered within 1-3 days. No deaths occurred during the study period. Two cardiovascularrelated adverse events were reported in the sitagliptin group (one myocardial ischaemia and one transient ischaemic attack); none were reported in the saxagliptin group.

Table 4. Safety profile

\begin{tabular}{lcc}
\hline Incidence, $n(\%)$ & $\begin{array}{c}\text { Saxagliptin }+ \text { metformin } \\
(n=403)\end{array}$ & $\begin{array}{c}\text { Sitagliptin }+ \text { metformin } \\
(n=398)\end{array}$ \\
\hline Any adverse event & $190(47.1)$ & $188(47.2)$ \\
Treatment-related & $21(5.2)$ & $30(7.5)$ \\
Any serious adverse event & $7(1.7)$ & $5(1.3)$ \\
Treatment-related & $1(0.2)$ & $2(0.5)$ \\
Deaths & 0 & 0 \\
Discontinuations due to adverse events & $9(2.2)$ & $9(2.3)$ \\
Most common adverse events $(\geq 2 \%)$ & & \\
Influenza & $23(5.7)$ & $23(5.8)$ \\
Urinary tract infection & $23(5.7)$ & $21(5.3)$ \\
Nasopharyngitis & $16(4.0)$ & $16(4.0)$ \\
Headache & $11(2.7)$ & $9(2.3)$ \\
Diarrhoea & $10(2.5)$ & $10(2.5)$ \\
Upper respiratory tract infection & $9(2.2)$ & $4(1.0)$ \\
Back pain & $7(1.7)$ & $10(2.5)$ \\
Nausea & $4(1.0)$ & $9(2.3)$ \\
Arthralgia & $2(0.5)$ & $10(2.5)$ \\
\hline
\end{tabular}

Hypoglycaemic adverse events occurred in 13 patients (3.2\%) in the saxagliptin plus metformin group and in 11 patients $(2.8 \%)$ in the sitagliptin plus metformin group. Most of the events were mild in intensity, although one patient in the sitagliptin group had a major hypoglycaemic event according to the Committee for Proprietary Medicinal Products classification. According to serious adverse events classified by system organ class or preferred term, two patients in the sitagliptin plus metformin group experienced hypoglycaemia.

The numbers of patients with skin disorders, based on either total adverse events in system organ class Skin and Subcutaneous Disorders or skin-related adverse events considered by investigators to be related to treatment, were slightly higher in the sitagliptin group compared with the saxagliptin group, but the differences were not considered clinically relevant (2\% for saxagliptin versus $5 \%$ for sitagliptin, and $0.7 \%$ for saxagliptin versus $1.5 \%$ for sitagliptin, respectively). Further, there were no clinically relevant mean changes from baseline haematology or clinical chemistry values, vital signs, electrocardiogram, or physical examination findings in either group. Body weight declined from baseline by a mean of $0.4 \mathrm{~kg}$ in both treatment groups. 


\section{DISCUSSION}

This study met its primary objective by showing that adding saxagliptin to metformin was noninferior to adding sitagliptin to metformin in reducing $\mathrm{HbA}_{1 \mathrm{c}}$ from baseline to week 18 in the per-protocol population, a finding confirmed in the full cohort analysis set. The two treatment groups were also comparable in the proportions of patients achieving a therapeutic glycaemic response (defined as $\mathrm{HbA}_{1 \mathrm{c}} \leq 6.5 \%$ ), and among those with baseline $\mathrm{HbA}_{1 \mathrm{c}} \geq 7.0 \%$ achieving a glycaemic response of $\mathrm{HbA}_{1 \mathrm{c}}<7.0 \%$. With the exception of modest differences in the FPG reduction, changes in all other secondary efficacy variables were similar between treatment groups. Therefore, the results of this study show that adding either saxagliptin or sitagliptin to a stable dose of metformin therapy similarly improves glycaemic control in patients with T2DM inadequately controlled by metformin alone.

Safety profiles were also similar with the addition of saxagliptin or sitagliptin to metformin therapy. The incidence and types of adverse events were comparable between treatment groups, and the frequency of serious adverse events was low with each treatment. Notably, the incidence of hypoglycaemic events was about 3\% in each group, and in all but one case (in the sitagliptin group), the events were minor hypoglycaemic events or events suggestive of hypoglycaemia according to the Committee for Proprietary Medicinal Products classification. While skin adverse reactions were more frequent in the sitagliptin group versus the saxagliptin group, the difference was not considered clinically relevant. Both DPP-4 inhibitors were well tolerated as reflected in the high rates of study completion $(>90 \%)$ and the low rates of discontinuation due to adverse events $(\leq 2 \%)$.

The results of the present study are similar to those of previous randomized, placebo-controlled clinical trials in which DPP-4 inhibitors were added to stable metformin therapy or used as initial therapy in combination with metformin [20]. The addition of saxagliptin to ongoing metformin therapy, compared with the addition of placebo, produced an adjusted mean change in $\mathrm{HbA}_{1 \mathrm{c}}$ of $-0.83 \%$ from a baseline of $8.1 \%$, and it allowed more than twice as many patients to achieve the goal of $\mathrm{HbA}_{\mathrm{lc}}<7.0 \%$ (43.5 versus $\left.16.6 \%\right)$ [7]. Similarly, the addition of $100 \mathrm{mg}$ /day sitagliptin to ongoing metformin therapy produced an adjusted mean change in $\mathrm{HbA}_{1 \mathrm{c}}$ of approximately $-0.7 \%$ from a baseline value of $8.0 \%$, and $-1.0 \%$ from a baseline of $9.3 \%$. Compared with placebo, the addition of sitagliptin allowed approximately $20-30 \%$ more patients to achieve $\mathrm{HbA}_{1 \mathrm{c}}$ levels $<7.0 \%$ $[11,21,22]$. In a 1-year noninferiority trial comparing $100 \mathrm{mg}$ /day sitagliptin with glipizide as add-on therapy to metformin, changes in $\mathrm{HbA}_{1 \mathrm{c}}$ from baseline (7.5\%) were $-0.67 \%$ at week 52 in both groups, with $63 \%$ of patients achieving $\mathrm{HbA}_{1 \mathrm{c}}<7.0 \%$ with sitagliptin and $59 \%$ with glipizide [23]. In another 1-year noninferiority trial, 50 $\mathrm{mg}$ vildagliptin twice daily added to metformin reduced $\mathrm{HbA}_{1 \mathrm{c}}$ from baseline $(7.3 \%)$ comparably to glimepiride added to metformin (-0.44 versus $-0.53 \%$ at week 52$)$, resulting in a similar proportion of patients reaching a target $\mathrm{HbA}_{1 \mathrm{c}}$ of $<7.0 \%$ with vildagliptin and glimepiride (54.1 and $55.5 \%$, respectively) [24]. In these studies, the tolerability of the DPP-4 inhibitors was generally comparable to that of placebo, with low incidences of hypoglycaemic events and small decreases in body weight; in addition, safety profiles were consistent with those observed with saxagliptin and sitagliptin in the present study, and further support the noninferiority of saxagliptin to sitagliptin [7,11]. Previous head-to-head trials have shown a much lower incidence of hypoglycaemic episodes with either sitagliptin [23] or vildagliptin [24] compared with sulphonylureas such as glipizide or glimepiride when added to metformin monotherapy.

Obesity is prevalent among patients with T2DM and the issue of weight control warrants further attention [25]. The absence of weight gain despite a significant improvement in glycaemic control represents an advantage of DPP-4 inhibitors compared with other oral glucose-lowering agents such as sulphonylureas $[23,24]$ or thiazolidinediones such as pioglitazone [26,27].

The primary limitation of this study is similar to that of other noninferiority trials: the exclusion of a comparator placebo group (in this case, placebo plus metformin). However, previously conducted placebo-controlled trials with both saxagliptin in combination with metformin [7] and sitagliptin in combination with metformin [11] provided necessary context for the design and conduct of this study. For example, as noted, the doses of each DPP-4 inhibitor used in this study - $5 \mathrm{mg}$ /day saxagliptin and $100 \mathrm{mg} /$ day sitagliptin - were previously shown to significantly improve glycaemic control as measured by decreases in $\mathrm{HbA}_{1 \mathrm{c}}$ and FPG compared with placebo, and by the higher proportions of patients achieving glycaemic goals compared with placebo within the setting of add-on therapy to metformin $[7,11]$. In these earlier placebo-controlled trials, adding a DPP-4 inhibitor to metformin reduced $\mathrm{HbA}_{1 \mathrm{c}}$ by -0.65 to $-1 \%$ compared with placebo $[7,11,21,22]$. $\mathrm{HbA}_{1 \mathrm{c}}$ was increased slightly or remained unchanged in the placebo groups of these studies. Thus, the improvements in $\mathrm{HbA}_{1 \mathrm{c}}$ achieved in the present study are consistent with the previous trials, especially when baseline $\mathrm{HbA}_{\mathrm{cc}}$ is taken into account in the analysis [28]. In addition, the safety profiles of the DPP-4 inhibitors can be placed into context on the basis of 
the previous placebo-controlled trials with saxagliptin or sitagliptin in combination with metformin. These earlier placebo-controlled trials showed that when added to metformin, DPP-4 inhibitors were well tolerated, and that their safety profiles were generally comparable to that of placebo $[7,11,21,22]$. Therefore, the adverse event profiles of saxagliptin and sitagliptin in the present study are consistent with the overall safety and tolerability of the DPP-4 inhibitor class observed in respective placebo-controlled studies.

In conclusion, the present study establishes the noninferiority of saxagliptin to sitagliptin when added to metformin therapy. The present study also showed that adding saxagliptin to stable metformin therapy was effective in lowering $\mathrm{HbA}_{1 \mathrm{c}}$ and was generally well tolerated in patients with T2DM whose glycaemia was inadequately controlled by metformin alone. Moreover, the addition of saxagliptin or sitagliptin to ongoing metformin treatment allowed clinically significant proportions of patients to achieve the glycaemic goal of $\mathrm{HbA}_{1 \mathrm{c}}<7.0 \%$ without causing hypoglycaemia or weight gain. These data provide further evidence supporting the clinical utility of the DPP-4 inhibitor-metformin combination.

\section{Acknowledgements}

The study was funded by AstraZeneca and Bristol-Myers Squibb. Technical and editorial assistance for this manuscript was provided by Gina Coviello, MS, Quintiles Medical Communications, Parsippany, NJ.

\section{Conflict of interest}

Andre J. Scheen has received honoraria for giving lectures and acting as a member of advisory boards for AstraZeneca/Bristol-Myers Squibb, Eli Lilly, GlaxoSmithKline, Merck Sharp \& Dohme (MSD), Novo Nordisk, Sanofi-Aventis, and Takeda. Guillaume Charpentier has been an investigator, consultant, or speaker for AstraZeneca, Bayer, Boehringer, Eli Lilly, Johnson \& Johnson, Medtronic, Merck Serono, Merck Sharp \& Dome (MSD), Novartis, Novo Nordisk, Pfizer, Roche, SanofiAventis, Siemens, and Takeda. Carl Johan Östgren has received honoraria for giving lectures and acting as a member of advisory boards for AstraZeneca, Bayer, Bristol-Myers Squibb, GlaxoSmithKline, Lilly, Merck Sharp \& Dohme (MSD), and Novo Nordisk. Åsa Hellqvist and Ingrid Gause-Nilsson are employees of AstraZeneca.

\section{References}

1. Nathan DM, Buse JB, Davidson MB, et al. Medical management of hyperglycemia in type 2 diabetes: a consensus algorithm for the initiation and adjustment of therapy: a consensus statement of the American Diabetes Association and the European Association for the Study of Diabetes. Diabetes Care 2009; 32: 193-203.

2. Rodbard HW, Jellinger PS, Davidson JA, et al. Statement by an American Association of Clinical Endocrinologists/American College of Endocrinology consensus panel on type 2 diabetes mellitus: an algorithm for glycemic control. Endocr Pract 2009; 15: 541-559.

3. Scheen AJ, Tan MH, Betteridge DJ, Birkeland K, Schmitz O, Charbonnel B, for the PROactive Investigators. Long-term glycaemic control with metformin-sulphonylurea-pioglitazone triple therapy in PROactive (PROactive 17). Diabet Med 2009; 26: 1033-1039.

4. Charpentier G, Halimi S, F-PIO-100 Study Investigators. Earlier triple therapy with pioglitazone in patients with type 2 diabetes. Diabetes Obes Metab 2009; 11: 844-854.

5. Flatt PR, Bailey CJ, Green BD. Dipeptidyl peptidase IV (DPP IV) and related molecules in type 2 diabetes. Front Biosci 2008; 13: 36483660.

6. Inzucchi SE, McGuire DK. New drugs for the treatment of diabetes: part II: incretin-based therapy and beyond. Circulation 2008; 117 : 574-584.

7. DeFronzo RA, Hissa M, Garber AJ, et al. for the Saxagliptin 014 Study Group. The efficacy and safety of saxagliptin when added to metformin therapy in patients with inadequately controlled type 2 diabetes on metformin alone. Diabetes Care 2009; 32: 1649-1655.

8. Chacra AR, Tan GH, Apanovitch A, Ravichandran S, List J, Chen R. Saxagliptin added to a submaximal dose of sul-phonylurea improves glycaemic control compared with uptitration of sulphonylurea in patients with type 2 diabetes: a randomised controlled trial. Int $J$ Clin Pract 2009; 63: 1395-1406.

9. Hollander P, Li J, Allen E, Chen R, for the CV181-013 Investigators. Saxagliptin added to a thiazolidinedione improves glycemic control in patients with type 2 diabetes and inadequate control on thiazolidinedione alone. J Clin Endocrinol Metab 2009; 94: 4810-4819.

10. Rosenstock J, Aguilar-Salinas C, Klein E, Nepal S, List J, Chen R. Effect of saxagliptin monotherapy in treatment-naive patients with type 2 diabetes. Curr Med Res Opin 2009; 25: 2401-2411. 
11. Charbonnel B, Karasik A, Liu J, Wu M, Meininger G. Efficacy and safety of the dipeptidyl peptidase-4 inhibitor sitagliptin added to ongoing metformin therapy in patients with type 2 diabetes inadequately controlled with metformin alone. Diabetes Care 2006; 29: 26382643.

12. Goldstein BJ, Feinglos MN, Lunceford JK, Johnson J, Williams-Herman DE. Effect of initial combination therapy with sitagliptin, a dipeptidyl peptidase-4 inhibitor, and metformin on glycemic control in patients with type 2 diabetes. Diabetes Care 2007; 30: $1979-1987$.

13. Januvia [package insert]. Merck \& Co, Inc: Whitehouse Station, NJ, 2008.

14. Augeri DJ, Robl JA, Betebenner DA, et al. Discovery and preclinical profile of Saxagliptin (BMS-477118) : a highly potent, long-acting, orally active dipeptidyl peptidase IV inhibitor for the treatment of type 2 diabetes. J Med Chem 2005; 48: 5025-5037.

15. Onglyza [package insert]. Bristol-Myers Squibb: Princeton, NJ, AstraZeneca: Wilmington, DE, 2009.

16. Dhillon S, Weber J. Saxagliptin. Drugs 2009; 69: 2103-2114.

17. Jadzinsky M, Pfützner A, Paz-Pacheco E, Xu Z, Allen E, Chen R, for the CV181-039 Investigators. Saxagliptin given in combination with metformin as initial therapy improves glycemic control in patients with type 2 diabetes compared with either monotherapy: a randomized controlled trial. Diabetes Obes Metab 2009; 11: 611-622.

18. Wallace TM, Levy JC, Matthews DR. Use and abuse of HOMA modeling. Diabetes Care 2004; 27: 1487-1495.

19. The European Agency for the Evaluation of Medicinal Products. Note for guidance on clinical investigation of medicinal products in the treatment of diabetes mellitus. May 2002. Available at: http://www.ema.europa.eu/pdfs/human/ewp/108000en.pdf. [4 May 2010].

20. Scheen AJ, Radermecker RP. Addition of incretin therapy to metformin in type 2 diabetes. Lancet 2010; $375: 1410-1412$.

21. Scott R, Loeys T, Davies MJ, Engel SS. Efficacy and safety of sitagliptin when added to ongoing metformin therapy in patients with type 2 diabetes. Diabetes Obes Metab 2008; 10: 959-969.

22. Raz I, Chen Y, Wu M, et al. Efficacy and safety of sitagliptin added to ongoing metformin therapy in patients with type 2 diabetes. Curr Med Res Opin 2008; 24: 537-550.

23. Nauck MA, Meininger G, Sheng D, Terranella L, Stein PP. Efficacy and safety of the dipeptidyl peptidase-4 inhibitor, sitagliptin, compared with the sulfonylurea, glipizide, in patients with type 2 diabetes inadequately controlled on metformin alone: a randomized, double-blind, non-inferiority trial. Diabetes Obes Metab 2007; 9: 194-205.

24. Ferrannini E, Fonseca V, Zinman B, et al. Fifty-two-week efficacy and safety of vildagliptin vs. glimepiride in patients with type 2 diabetes mellitus inadequately controlled on metformin monotherapy. Diabetes Obes Metab 2009; 11: $157-166$

25. Scheen AJ. Current management strategies for coexisting diabetes mellitus and obesity. Drugs 2003; 63: $1165-1184$.

26. Bolli G, Dotta F, Colin L, Minic B, Goodman M. Comparison of vildagliptin and pioglitazone in patients with type 2 diabetes inadequately controlled with metformin. Diabetes Obes Metab 2009; 11: 589-595.

27. Scheen AJ, Tan MH, Betteridge DJ, Birkeland K, Schmitz O, Charbonnel B. Long-term glycaemic effects of pioglitazone compared with placebo as add-on treatment to metformin or sulphonylurea monotherapy in PROactive (PROactive 18). Diabet Med 2009; 26: 12421249.

28. Chapell R, Gould AL, Alexander CM. Baseline differences in A1C explain apparent differences in efficacy of sitagliptin, rosiglitazone and pioglitazone. Diabetes Obes Metab 2009; 11: 1009-1016. 